\title{
Reestructuración urbana de un territorio glocalizado: una caracterización del crecimiento orgánico en las ciudades de Chiloé, 1979-20081
}

\author{
Jonathan Barton², Ricardo Pozo ${ }^{3}$, Álvaro Román ${ }^{4}$ y Alejandro Salazar ${ }^{5}$
}

\begin{abstract}
RESUMEN
El archipiélago de Chiloé ha experimentado profundos cambios socioespaciales desde los años ochenta. La localización y la progresiva consolidación de la industria del salmón cambiaron la velocidad y la composición de la urbanización en la provincia, surgiendo nuevas formas de ocupar el espacio. Se evidencia una nueva tipología urbana en la provincia caracterizada por nueve formas de ocupación. Esta tipología surge de un análisis de la evolución morfológica de cinco ciudades por medio de herramientas SIG. El artículo concluye que la inserción de ciudades medianas y pequeñas en los circuitos o redes de acumulación de capital global sucede a una velocidad alta, dejando atrás la planificación urbana, una función pública. Como consecuencia, la planificación urbana termina siendo un instrumento de reconocimiento del crecimiento urbano orgánico y no de regulación y orientación del crecimiento. Esta situación de velocidades diferenciadas genera desequilibrios que influyen negativamente en la posibilidad de crear procesos de desarrollo urbano más sustentables.
\end{abstract}

Palabras clave: Chiloé, crecimiento urbano, glocalización, morfología urbana.

\begin{abstract}
Chiloé archipelago has experienced profound socio-spatial changes since the early 1980s. The localization and progressive consolidation of the salmon industry changed the velocity and composition of the urbanization process in the province, generating new forms of spatial occupation. This can be seen in a new urban typology characterized by nine forms of occupation. This typology emerges from an analysis of the morphological evolution of five cities using GIS. The article concludes that the insertion of small and medium size cities in circuits, or networks of global capital takes place at a high velocity, leaving urban planning, a public function, behind. Consequently, urban planning ends up as an instrument of recognition of organic urban growth and not of regulation and growth orientation. This situation of differentiated velocities generates disequilibria that negatively affect the possibilities of creating more sustainable urban development processes.
\end{abstract}

Key words: Chiloé, urban growth, globalization, urban morphology.

\footnotetext{
1 Los autores agradecen el apoyo y financiamiento del Proyecto FONDECYT Regular 2010 No 1100519 y CONICYT/FONDAP/15110020 y CONICYT-PCHA/ Doctorado Nacional/2013-21130416 y la colaboración de Felipe Irarrázaval I. (Instituto de Estudios Urbanos y Territoriales UC) y Camila Ugarte A (Instituto de Geografía UC). Artículo recibido el 8 de mayo de 2013, aceptado el 15 de abril de 2013 y corregido el 30 de mayo de 2013.
}

2 Centro de Desarrollo Urbano Sustentable (CEDEUS) e Instituto de Estudios Urbanos y Territoriales, Pontificia Universidad Católica de Chile (Chile). E-mail: jbarton@uc.cl

3 Instituto de Planificación Urbana y Regional, Universidad Católica de Santiago de Guayaquil (Ecuador). E-mail: ricardo.pozo@cu.ucsg.edu.ec

4 Instituto de Estudios Urbanos y Territoriales, Pontificia Universidad Católica de Chile (Chile). E-mail: ajroman@uc.cl

5 Instituto de Geografía y Pontificia Universidad Católica de Chile (Chile) E-mail: asalazab@uc.cl 
El inicio y la progresiva consolidación de la industria del salmón desde los inicios de los 80 en Chiloé ha detonado importantes transformaciones socioespaciales en su sistema de centros poblados. Esta actividad productiva ha revalorizado la funcionalidad del suelo urbano con inversiones directas en plantas, e indirectamente a través de las migraciones relacionados con las oportunidades laborales asociadas, dentro la provincia y desde afuera. Como consecuencia, las cabeceras comunales han experimentado acelerados procesos de urbanización caracterizados por la reconfiguración de sus centros poblados y la expansión física hacia sus periferias rurales (Arenas et al., 2001a; Arenas et al., 2001b; Fløysand \& Román, 2008). Estas dinámicas se traducen, a su vez, en nuevas formas de ocupar el espacio, generando una nueva tipología de asentamiento.

Este artículo identifica los tipos de crecimiento urbano (TCU) presentes en cinco ciudades de Chiloé durante el período 19792008. El argumento es que estos conforman una nueva tipología urbana característica del sistema de poblados chilote en un momento histórico relevante que coincide con el nacimiento, auge y crisis de la salmonicultura. Por medio del análisis de los TCU identificados se buscó comprender la naturaleza del nuevo proceso urbano desplegado en Chiloé y las tensiones entre la fluidez y velocidad del despliegue del capital asociado con el sector, y la planificación urbana de los poblados durante el mismo proceso. Las ciudades de Castro, Dalcahue, Quellón y Quemchi fueron elegidas por su especial concentración de mutaciones durante el último periodo y su estrecho vínculo con los centros de cultivo, faenado y comercialización del salmón de exportación chileno; Ancud es la excepción debido al impacto de la miticultura más que la salmonicultura, pero hay procesamiento de salmones dentro la comuna.

La salmonicultura se encuentra intensamente relacionada a procesos globales (de inversiones, tecnologías y ventas), pero se vincula débilmente con el entorno local del cual extrae recursos y explota capital humano, relegando responsabilidad para el desarrollo urbano local a las autoridades públicas (Barton, 1997; Fløysand et al., 2010a; Fløysand et al., 2010b). Aplicando el concepto de gloca- lización de Swyngedouw (2004), se sostiene que los procesos de acumulación de capital global -caracterizado por 'espacios de redes' según Swyngedouw- en este caso acuícola, tienen una velocidad de movilización e impacto que supera los procesos más lentos de regulación -'espacios de regulación' - en este caso la planificación urbana de poblados de tamaño medio y pequeño. Es precisamente este desequilibrio de velocidades, entre la velocidad de capital en su transformación territorial versus la velocidad de la planificación urbana en ordenar el territorio, lo que genera un crecimiento orgánico de las ciudades. Este crecimiento orgánico transciende las capacidades públicas de ordenar el espacio, generar infraestructura y servicios, y consolidar una morfología y 'oferta' urbana capaz de mejorar la calidad de vida y generar un desarrollo urbano más sustentable. Este artículo analiza esta relación, entre la inserción de un territorio en la economía global bajo una lógica de acumulación de capital intensiva y veloz, versus la capacidad -limitada y lenta- de planificar y regular el territorio desde el Estado.

En base a la observación e interpretación de fotografías aéreas del Servicio Aerofotogramétrico de la Fuerza Aérea de Chile (SAF) de los años 1979-1980 y 1994-1995 y de imágenes satelitales de Google Earth para 2002, 2005 y 2008, se identificó el crecimiento y consolidación de diversas formas urbanas. Se demuestra que existe un cambio en el ritmo de crecimiento de las ciudades relacionado con la presencia del capital acuícola, el cual transforma el espacio físico local para su reproducción. A pesar de la implementación por primera vez, o de la actualización de los planos reguladores comunales (PRC) o de los límites urbanos (LU) en las cinco ciudades durante la segunda y tercera década del boom salmonero, el proceso de expansión desordenada (orgánica) no decreció sino que, por el contrario, estos instrumentos ampliaron significativamente los bordes de las ciudades incorporando grandes superficies de suelo urbanizable. Se identificaron nueve TCU observados en el período 1979-2008, los cuales varían en intensidad de acuerdo a condicionantes naturales, como la topografía, o artificiales, influidos pero no totalmente regulados por los instrumentos de planificación territorial (IPT). Esta nueva tipología está explicada desde una crítica de las relaciones 
entre capital y el Estado, en particular las velocidades de planificación y operación de las dos fuerzas, y las responsabilidades que surgen en términos del desarrollo urbano sustentable.

\section{Morfología urbana y el rol transformador del capital}

El foco de atención en el presente trabajo está sobre la morfología urbana y las fuerzas que influyen en su configuración. La morfología puede ser el punto de partida o de término para estudiar diferentes procesos, como la organización económica, social o las estructuras políticas (Capel, 2002). En ese sentido, para poder vincular el análisis de las transformaciones del espacio urbano en Chiloé con el rol de la acumulación de capital, es necesario vincular la geografía urbana relacionada con formas urbanas, y la geografía económica relacionada con los procesos de globalización (Harvey, 2004; Swyngedouw, 2004).

Wheeler (2008), Capel (2002), y Gauthier \& Gilliland (2006) afirman que se pueden reconocer dos corrientes teóricas respecto a la morfología urbana: la normativa-visionaria y la histórica-descriptiva. En la primera se agrupan quienes plantearon propuestas teóricas de formas urbanas ideales, las cuales se orientan a lograr ciudades más factibles de ser vividas por sus habitantes, las Ilamadas 'utopías'. Como respuesta a la contaminación y hacinamiento de la ciudades victorianas europeas y americanas del siglo XIX surgen los primeros idealistas de formas urbanas con trasfondos más profundos (Hall, 1996). Había dos corrientes: la corriente de escapar la ciudad urbano-industrial tradicional para crear una alternativa híbrida, como en el caso de las ciudades jardines (New Towns) de Ebenezer Howard, las nuevas capitales mundiales (de Canberra, Brasilia, Abuja, etc.) y 'eco-aldeas'; y la corriente de trabajar con el mejoramiento de lo existente, e.j. la ciudad higiénica, 'nuevo urbanismo', 'smart growth'. En ambos casos, la planificación fue central, pero a diversas escalas, desde la ciudad regional de Patrick Geddes al barrio del 'smart growth'.

En promover la planificación había un reconocimiento de la velocidad de las trans- formaciones urbano-industriales previas en términos de industrialización, masiva inmigración y los problemas asociados en términos de salud y bienestar debido a la falta de planificación y un crecimiento orgánico (documentado en detalle en 1845 por Engels, 2009). Es precisamente esta tensión entre la acumulación de capital asociada con nuevas inversiones, nuevos flujos demográficos y un desarrollo urbano más sustentable que constituye la base de los debates sobre el desarrollo urbano-regional desde los 50. Estos debates surgen en el contexto de la internalización de producción, el Nuevo Orden Económico Internacional, y los procesos de globalización contemporánea (Dicken, 2011; Murray, 2006), donde diversos territorios fueron insertos en los circuitos de capital internacional y las cadenas de producción (Gereffi \& Korzeniewicz, 1994); los centros poblados, como espacios articuladores y nodos de estos territorios, fueron transformados en el proceso. Muchos de ellos siguen siendo de tamaño mediano y pequeño mientras que su rol en los procesos de globalización es de gran relevancia. En las discusiones sobre lo que se puede Ilamar 'la periferia de recursos' (Barton et al., 2007; Barton et al., 2008), estas ciudades son constituidas como nodos en las redes construidas a través de la globalización neoliberal, y sufren de su estatus como puntos de extracción de riqueza y beneficios exhibiendo poca evidencia de un desarrollo in situ. Comúnmente forman territorios 'en red', policéntricos, donde múltiples centros participan en una sola lógica productiva, tanto textil, como pesquera, agrícola o minera. La OCDE ha identificado que el aporte de estas ciudades de menor tamaño sigue siendo vital para las economías en desarrollo, donde se ha subestimado este rol dentro de la planificación urbano-regional nacional; en el caso de Chile, el National Urban Policy Review de la OCDE enfatiza claramente esta importancia (World Bank, 2009; Maturana y Arenas, 2012; OCDE, 2013). Por lo general, estas ciudades muestran una falta de planificación normativa visionaria, quedando sujetos a procesos orgánicos generados por nuevos flujos de capital. Hay poca evidencia de lo que Lynch (1981) y Wheeler (2008) plantean como ciudades vivibles, caminables y sustentables.

El estudio histórico-descriptivo de las ciudades posee gran recorrido dentro de las 
investigaciones en geografía y urbanismo. En efecto, los primeros estudios de morfología urbana se desarrollan desde la tradición regional historicista, de Carl Sauer, Max Sorre, Pierre George, y el manejo del concepto de Landschaft o paisaje. Posteriormente, se agregan los estudios más cuantitativos, o neopositivistas, como en el caso del trabajo de Peter Haggett, seguidos por los análisis más radicales asociados con los actores urbanos y el tejido urbano que supera solamente la forma (Harvey, 1973; Levy, 1999; Capel, 2002). A través de la morfología se puede entender este conjunto de elementos asociados con las transformaciones del espacio: cultura, economía y los procesos sociopolíticos. En términos generales, el estudio de la morfología urbana adopta dos líneas de exploración: el historicista (Whitehand, 2009), y el cuantitativo y taxonómico (ej. unidades estructurales urbanas (UEU) y 'space syntax', ver Osmond, 2010, Gil et al., 2012), con diferenciaciones cognitivas versus normativas, 'internalista' (análisis de caso) versus 'externalista' (comparativo) (Gauthier \& Gilliland, 2006). El estudio del desarrollo de las formas urbanas según las transformaciones históricas ofrece una plataforma importante para análisis comparativo, dentro de países y en forma internacional (Kropf, 2001; Oliveira, 2013). A través de estos análisis, se pudieron construir tipologías de forma urbana y 'morfogenética' (Kropf, 2009; Ehlers, 2011), por ejemplo las categorías de Korcelli (en Ehlers, 2011): socioecología y modelos socioespaciales; modelos de transporte y uso de suelo; densidad poblacional; interacción intraurbana; análisis y diferenciación de lugares centrales; y modelos de difusión intraurbano. El estudio de morfología urbana, desde sus raíces en Alemania al principio del siglo XX, ha sufrido de una 'miopía euro-americano' (siendo norteamericano), y anglófono, según Whitehand (2012: 58), y todavía hay relativamente poca investigación en contextos de países en desarrollo (Vernez, 1997; Gauthiez, 2004).

Este análisis de la evolución morfológica de las ciudades de Chiloé durante el acelerado proceso de reconfiguración geográfica experimentado recientemente, se alinea fundamentalmente con la corriente histórico-descriptiva de la forma y tejido urbano. Desde esta corriente, el trabajo se basa principalmente en los estudios con- temporáneos de las metrópolis anglosajonas que enfatizan los avances tecnológicos de las últimas dos décadas en los sistemas de información geográfica (SIG), aunque con un enfoque adaptado por escala menor y contexto chileno (Wheeler, 2008). Los SIG pueden cuantificar el consumo de suelo y las nuevas superficies urbanas agregadas a las ciudades. Adicionalmente, esta información puede ser intercalada con otras fuentes, como son datos socioeconómicos, de infraestructura, acceso a servicios, vulnerabilidad social, etc. De este modo se obtiene una importante base de datos que permite interpretar el crecimiento de los espacios construidos y así generar análisis e interpretaciones de mayor profundidad en lo que respecta a los gestores y los procesos urbanos.

Esta evidencia empírica permite graficar los argumentos de David Harvey (2004) y, particularmente, de Erik Swyngedouw (2004) respecto al poder transformador de las ciudades del capital mediante redes multiescalares. Las transformaciones socioespaciales se visualizan físicamente en la fragmentación espacial de ciudades contemporáneas en diversas formas urbanas caracterizadas por atributos especiales, como son sus tramas viales, tamaño y forma de los lotes, diseños de los emplazamientos y mixturas en los usos de suelo. Harvey (2004) constata que es justamente en las ciudades en donde se concentra el futuro de la civilización mundial debido a que rápidamente estamos pasando a ser más urbanizados y menos rurales. En el caso de Chiloé, esta visión histórico-descriptiva de las nuevas formas urbanas se adapta al contexto de mutación de la geografía económica del territorio debido a la influencia de la salmonicultura, y la velocidad del impacto en este. A pesar de ser ciudades pequeñas, experimentan un proceso de fragmentación espacial en el que es posible distinguir secciones características.

El análisis de las nuevas capas históricas que surgen permite evaluar el efecto físico del capital sobre el espacio urbano y, mediante una reflexión crítica, es posible establecer las conexiones entre las nuevas formas de las ciudades y su participación en cadenas transnacionales de valor (Gereffi \& Korzeniewicz, 1994). Esta vinculación ocurre en la medida que se configura una particular 
sinergia entre escalas de regulación y escalas producción de redes que Swyngedouw (2004) define como glocalización. Por un lado, el sector público busca medios por los cuales garantizar los procesos de acumulación de capital y resolver problemáticas de carácter nacional y local mediante formas de regulación a distintas escalas. Por otro, el sector privado, en especial empresas transnacionales, encuentra un terreno fértil en el cual desplegar sus actividades productivas con cierta flexibilidad para operar en el territorio (Swyngedouw, 2004; Van Apeldoorn et al., 2012).

El capital ha transformado la economía tradicional de Chiloé basada en la agricultura y la pesca de autoconsumo y, en el proceso, también modificó sus patrones de alta ruralidad, de emigración laboral hacia la Patagonia chilena y argentina, y de poblados interconectados por rutas marítimas (Grenier, 1984; Gobantes, 2012; Montiel, 2010). La actividad salmonera ha generado grandes cambios en el sistema económico y en las relaciones sociales al interior de la isla (Román, 2009). Las actividades productivas tradicionales que durante siglos constituyeron la base de la economía chilota se vieron afectadas por el establecimiento de una industria altamente competitiva, globalizada y manejada por capitales nacionales y transnacionales (Amtmann \& Blanco, 2001; Barrett et al., 2002). Las ventajas comparativas de esta industria pueden explicarse por tres motivos fundamentales. En primera instancia, destacan las particulares condiciones hidrobiológicas, la producción contra cíclica y los bajos costos de producción y transporte (Barton, 1998). En segundo lugar, por las ventajas comparativas de naturaleza institucional, como las bajas regulaciones ambientales y laborales a la actividad (Barrett et al., 2002), y en tercer lugar, el liberal marco normativo que rige la asignación de los recursos marinos en Chile (lizuka, 2004; Katz, 2006). Este tipo de ventaja tendría a la industria operando bajo una suerte de "dumping social y ambiental" en Chile, que le permitiría compensar la mayor distancia que separa al salmón chileno de los principales mercados de destino (Ramírez et al., 2009:7). Estas condiciones han permitido la deslocalización productiva de los principales productores de salmones del mundo y de parte de sus inversiones sobre el archipiélago de Chiloé en las últimas tres décadas.

Tras la consolidación del mercado del salmón, el mercado laboral de la provincia se expandió, alcanzando a localidades rurales que experimentaron este tipo de intercambio por primera vez. Como consecuencia, generó oportunidades para la población joven que antes migraba del archipiélago y atrajo población desde otras partes del país e incluso de otros países de la región. Esto provocó un visible aumento demográfico en los principales centros urbanos y el surgimiento de nuevas formas de ocupación del espacio urbano y rural así como conflictos ambientales y culturales (ver Figura $N^{\circ} 1$ ). La velocidad y el contenido de la urbanización en sus principales ciudades (como en otras de rango menor) cambiaron significativamente y junto a la presencia de una actividad económica glocalizada, han generado una profunda reestructuración geográfica de los territorios. La expansión de los centros urbanos y la densificación de los asentamientos humanos ya existentes localizados en sus alrededores ha alcanzado espacios rurales donde históricamente se asentaron comunidades campesinas con cultura y dinámicas productivas propias. Villorrios y pequeños poblados rurales próximos a las ciudades reciben nuevos habitantes como consecuencia de la demanda de suelo a bajo costo motivado por las oportunidades de trabajo que las pequeñas aglomeraciones urbanas de la costa oriental del archipiélago ofrecen durante el auge del boom salmonero.

Esta expansión acelerada, desorganizada e informal de determinados tipos de crecimiento urbano significa mayores costos a largo plazo para la administración pública local en abastecimiento de servicios e infraestructura. La planificación urbana en Chiloé ha sido sobrepasada por las transformaciones que ha experimentado, limitándose a normar el uso de suelo de manera tardía y a incrementar el suelo urbanizable, especialmente en comunas como Quellón, Dalcahue y Quemchi, donde no existió regulación en el período de expansión de la actividad industrial. Junto a los conflictos entre las estrategias de desarrollo, en Chiloé también se observa procesos de deterioro ambiental. Es importante destacar que el paso a una sociedad más urbana trae consigo procesos territoriales como 
Figura $\mathrm{N}^{\circ} 1$

Evolución de la población comunal en cinco comunas de Chiloé, 1982-2012.

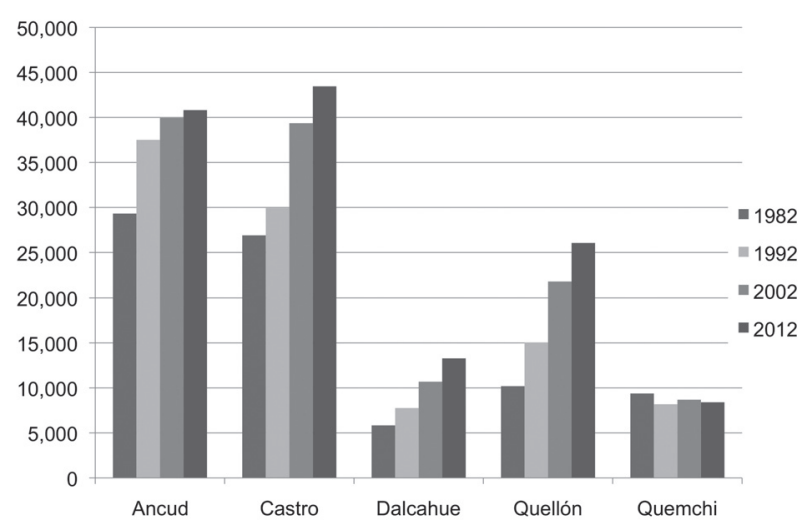

Fuente: Elaboración propia con base en INE $(2012,2003,1993$, 1982).

la rurbanización, caracterizada por los efectos del crecimiento acelerado de las ciudades (Bailly, 2009; Bailly \& Bourdeau-Lepage, 2011), y de las nuevas ruralidades, en que se solapan prácticas y procesos que típicamente han estado asociados a modos de vida ya sean tradicionales o urbano-industriales (Kay, 2008). Las ciudades chilotas inician así un acelerado crecimiento, presionando a las zonas rurales y sus actividades. Este proceso ha tenido beneficios, como la fuerte disminución de la pobreza y el desempleo, y el desarrollo de una economía de servicios alrededor de la salmonicultura. Por otra parte, ha vuelto muy dependiente a la provincia de esta actividad, y el proceso de urbanización ha tenido un fuerte impacto en la cultura chilota asociada con tradiciones y prácticas.

\section{Criterios de definición de TCU}

La evolución de las transformaciones espaciales en las cinco ciudades se observa por medio de la fotointerpretación sobre fotografías aéreas del Servicio Aerofotogramétrico de Chile (SAF). Se seleccionaron fotos aéreas para cada caso obtenidas en 1979-1980 y 1994-1995 a escalas 1:20.000 y 1:30.000 respectivamente. Para el período año 20022008 se escogieron imágenes satelitales del archipiélago obtenidas mediante el software Google Earth. Para las cinco ciudades seleccionadas se identificó TCU que caracterizan las nuevas manchas urbanas que se extienden por las periferias urbanas o rururbanas en el período 1979-2008. De los estudios realizados por Munizaga (1993) en Chile, de SoláMorales (1997) en España o Wheeler (2008) en Estados Unidos se desprende que los TCU son herramientas pertinentes para la interpretación de la forma urbana (ver también, Kropf, 2009). De acuerdo a cada caso de estudio y a la disponibilidad e importancia de la información, dichos investigadores han determinado aquellos atributos de la morfología urbana bajo análisis que les permiten contrastar más claramente las diversas formas que la componen. Para la clasificación de los TCU en Chiloé se determinaron previamente los atributos que cada trama urbana debe poseer para ser diferenciada. Estos son: forma de trama vial (distribución regular o irregular, lineal, sinuosidad, manzanas (forma y tamaño), lotes (forma y tamaño), edificaciones (formas homogéneas o heterogéneas), ocupación de suelo (alta, media o baja huella constructiva).

Al igual que en el trabajo de Wheeler (2008), no se considera como parte de los TCU los espacios abiertos como parques, canchas, plazas, cementerios o áreas verdes. Cada TCU es seleccionado en polígonos sobre las fotografías digitales por medio del software ArcMap 10. El criterio de identificación de los límites de cada uno de ellos se basa en la variación extrema y marcada de atributos (Wheeler, 2008). Adicionalmente, se incorporó como TCU a los asentamientos 
humanos tipo leapfrog, es decir, aquellos discontinuos en relación a la trama urbana. El criterio para su selección se basa en la intensidad de la relación de flujos de bienes, información o personas. Para el presente estudio se considera como principales factores motrices los cambios acelerados de forma y densidad poblacional de asentamientos satelitales cercanos a los centros urbanos. De forma complementaria al trabajo de fotointerpretación y sistematización en SIG, se recopiló información de campo para verificar ciertos patrones en diversas entrevistas con funcionarios municipales encargados de la planificación urbana. También se revisó en los planos topográficos el relieve natural del emplazamiento en donde se ha desarrollado cada ciudad para identificar pendientes elevadas, quebradas, bordes costeros inundables y perfiles de ríos inundables. Adicionalmente se consideró la información contenida los planos de los LU y PRC actualizados.

\section{Tipos de crecimiento urbano en Chiloé}

Del análisis espacial de los patrones de asentamiento urbano en las ciudades estudiadas fue posible identificar 9 TCU (identificadas correlativamente con las letras A-I) que caracterizan las prácticas contemporáneas de ocupación del espacio en una provincia que ha experimentado sus mayores transformaciones en el curso de solo tres décadas. Esta ocupación ha sido impulsada por el crecimiento orgánico por sobre la limitada planificación urbana, con una velocidad definida por las inversiones de capital salmonícola y no por los plazos de la administración pública. Se trata de tramas en las que los centros urbanos se han consolidado en términos de densificación y de expansión, aunque la conectividad terrestre es clave para entender nuevos usos de suelo más intensivos. Este crecimiento urbano es gatillado por una mayor demanda por suelo residencial, la introducción de proyectos masivos de vivienda social, la necesidad de sortear la difícil topografía especialmente en zonas costeras-, población inmigrante de otras zonas del país que busca una manera no tradicional de residir, la localización de grandes inversiones industriales y la persistencia de población que no ha sido beneficiada por el crecimiento económico y que busca alternativas de localización que presionan aún más a los IPT. Estos fenómenos son representados en los siguientes TCU.

\section{Reconfiguración de núcleo}

La reconfiguración de la trama urbana existente a inicios de la década de 1980 se produce por la subdivisión de lotes existentes y el incremento de la ocupación del suelo urbano dentro de las manzanas y de los propios lotes. Esto se puede observar por el aumento en la superficie construida dentro de las manzanas, específicamente en el número de viviendas. Una posibilidad es que los propietarios de los lotes urbanos venden o alquilan espacios en la parte posterior de sus terrenos ante la explosiva demanda de hospedaje temporal o fijo por parte de inmigrantes atraídos por la actividad salmonera, como también existe la subdivisión predial producto de la sucesión familiar. Para poder crear más frentes de lotes, las pocas macromanzanas identificadas se subdividen por la construcción de calles transversales. La presión sobre el suelo urbano genera su valorización y, por consiguiente, demanda su máximo aprovechamiento. La morfología urbana resultante para el año 2005 corresponde a centros urbanos con tramas irregulares con un alto porcentaje de ocupación del suelo por manzana y densamente poblados. Se incorpora un mayor uso comercial, en especial en calles y avenidas importantes como costaneras, vías de acceso a la ciudad y transversales cercanas a edificios públicos de importancia o hitos urbanos (ver Figura $N^{\circ} 2$ ).

\section{Extensión de núcleo}

De forma paralela a la densificación del centro urbano y reconfiguración de su trama original, a la superficie urbana existente se agregan nuevos asentamientos al borde de vías principales. Se produce la parcelación de terrenos agrícolas adjuntos a la ciudad para la conformación de lotes urbanos. Durante el primer período 1979-1995 estos asentamientos se convierten en manzanas al trazarse calles en ellos. Son de formas rectangulares que se adaptan al relieve de pendientes o bordean ríos que desembocan en el mar. Se observa en el trazado de las vías una búsqueda por mantener la continuidad geométrica de la 
Figura $\mathrm{N}^{\circ} 2$

Reconfiguración de núcleo en Quellón, 2005.

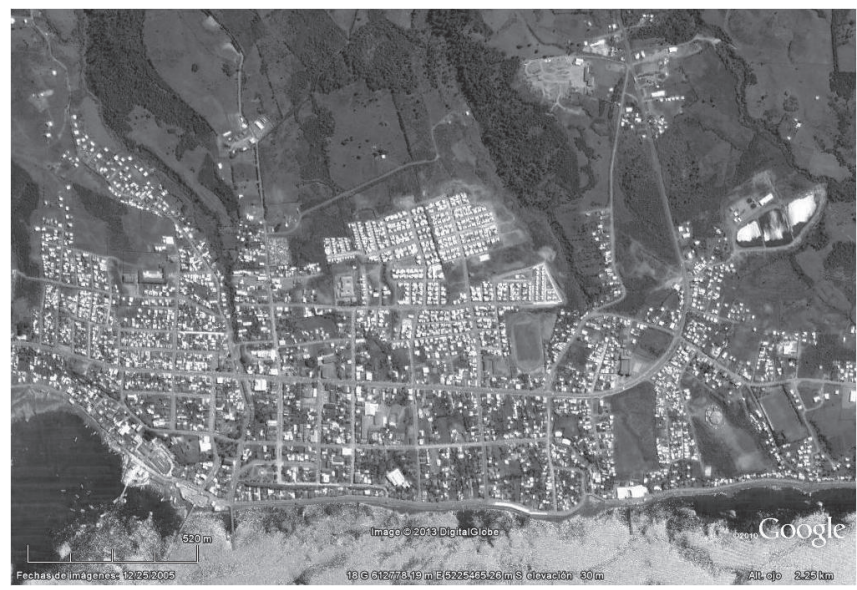

Fuente: Imagen satelital de 2005 (Google Earth).

trama urbana existente en el centro urbano al cual se adjunta. Para el segundo período, 1996-2005, estas formas urbanas se encuentran mucho más consolidadas y se observan como una continuidad de la ciudad (ver Figura $\mathrm{N}^{\circ} 3$ ).

Predomina el uso de suelo residencial, pero se incorpora de forma progresiva el uso de suelo comercial en las vías principales y de acceso a la ciudad. Estos nuevos terrenos para urbanizar son aprovechados también para la construcción de infraestructura y equipamiento urbano. La razón de localizarse junto a la trama urbana existente responde a una lógica de beneficiarse de forma directa de los servicios básicos existentes, como agua potable, alumbrado público y alcantarillado

Figura $\mathrm{N}^{\circ} 3$

Extensión de núcleo en Dalcahue 1980-2005.

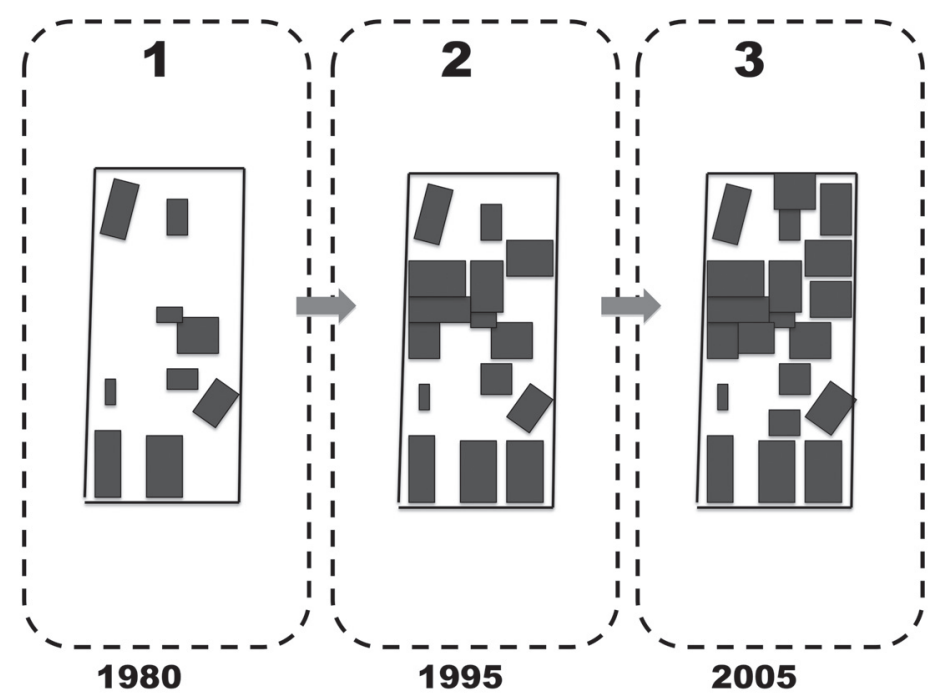

Fuente: Elaboración propia con base en fotos aéreas de 1980 y 1995 (SAF) e imagen satelital de 2005 (Google Earth). 
en determinadas ciudades. En Dalcahue y Quellón los instrumentos de planificación son bastante recientes (LU desde 2003 y PRC desde 2005, respectivamente), por lo que la mayor parte del desarrollo de su expansión urbana se dio sin instrumentos de planificación que la normen. En el caso de Quemchi, esta tipología se produce en un grado mucho menor, limitada por el emplazamiento topográfico. Las manzanas se incrementan hasta una determinada distancia pues las fuertes pendientes vuelven difícil su ocupación. En Castro y Ancud la expansión periférica a sus centros urbanos se da con una mayor intensidad. La forma urbana resultante de este tipo de crecimiento es más coherente con la trama urbana existente. Esto supone costos razonables de inversión pública para el abastecimiento de servicios e infraestructura urbana, pues en buena parte se aprovecha la existente.

\section{Expansión tentacular}

Otro tipo de crecimiento urbano identificado es el tentacular. Este se caracteriza por la concentración al pie de vías principales de acceso al poblado de asentamientos. Se produce la parcelación progresiva de franjas de terreno que bordean las vías de acceso a las ciudades. Estos nuevos lotes poseen una forma rectangular irregular y una mínima huella de construcción en su interior. Por ello, se puede interpretar que es un tipo de parcelación sin planificación técnica. A pesar de que la subdivisión de terrenos agrícolas puede ser legal o ilegal, su irregularidad formal denota que estas parcelaciones se dan en base a los trazados de los mismos propietarios. Muchos lotes mantienen actividades primarias agrícolas y/o ganaderas. Se puede decir que son pequeñas granjas adosadas a las vías de acceso a la ciudad y a sendero o caminos secundarios que las conectan (ver Figura $N^{\circ} 4$ ).

Predomina el uso de suelo residencial. Sin embargo, en determinados sectores surge el uso comercial e incluso industrial. Grandes paños de terreno ubicados al pie de vías son utilizados como parqueo de maquinaria, equipos e implementos relacionados a la producción industrial. Estos asentamientos tentaculares también se pueden distribuir de forma dispersa. Es decir, comienzan a surgir pequeñas islas de asentamientos a lo largo de la vía sin una secuencia o conexión espacial con el centro urbano existente. En el caso de la ciudad de Quemchi, este TCU predomina ampliamente. La forma de esta ciudad es prácticamente la de un gran tentáculo que bordea el perfil costero de sur a norte, oscilando conforme a la sinuosidad topográfica para decantar en su núcleo urbano emplazado en una pequeña punta. Se puede decir que la agreste topografía del sector donde se emplaza Quemchi la atrapó entre las sinuosas lomas y el borde costero. En las otras ciudades también se produce este tipo de crecimiento. En Ancud, Castro, Dalcahue y

Figura $\mathrm{N}^{\circ} 4$

Crecimiento tentacular disperso en Quemchi, 2002.

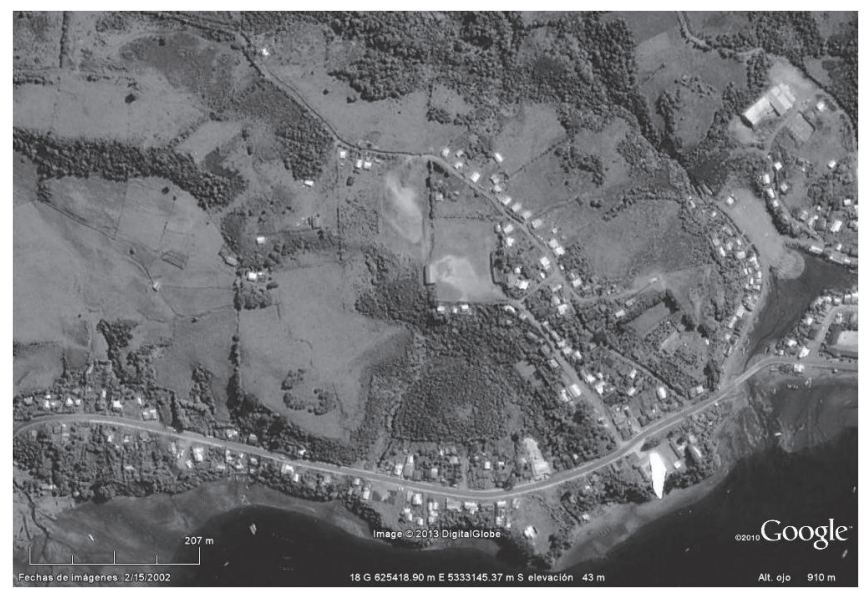

Fuente: Imagen satelital de 2002 (Google Earth). 
Quellón se producen formas tentaculares en sus accesos principales desde la Ruta Panamericana y en las vías de interconexión con otros poblados cercanos.

Esta forma urbana es la que probablemente ha demandado más costos de inversión pública. Aunque la mayoría se desarrolla fuera de los límites urbanos, su consolidación progresiva trajo consigo la exigencia de los habitantes de ser incorporados formalmente al suelo urbano $y$, por tanto, ser abastecidos por servicios básicos, equipamiento e infraestructura pública. Por ser asentamientos de baja densidad y gran superficie, la distribución de redes de agua potable, alcantarillado, alumbrado público y vialidad implica importantes gastos para las administraciones locales y para los servicios privatizados. De acuerdo a entrevistas realizadas durante la investigación de campo en Chiloé, funcionarios municipales de planificación urbana de Quemchi y Quellón comentaron respecto a casos en que empresas de servicio de agua potable se resisten a abastecer determinados sectores. Esto sucede pues no les es rentable abastecerlos dados los altos costos de inversión en implementación de redes.

\section{Expansión capilar}

El tipo de crecimiento urbano capilar debe su nombre a su forma y dinámica de desplegarse sobre la difícil topografía local. Aunque nacen por su cercanía a vías principales de acceso a las ciudades, al igual que las formas tentaculares, este tipo de crecimiento se diferencia porque nace de vías secundarias, caminos o senderos que parten interceptando las vías de acceso a los centros urbanos, para después adentrarse a través de una topografía agreste. La configuración de su trama vial es similar a la de capilares que brotan de sí mismos constantemente (ver Figura $\mathrm{N}^{\circ} 5$ ).

En este caso, la topografía juega un rol como condicionante en la configuración del espacio construido. La forma capilar se adapta a la topografía sin aplicar soluciones constructivas como terrazas o movimientos de tierra considerables. Simplemente la expansión urbana se acomoda a las sinuosas lomas que caracterizan el perfil costero oriental del archipiélago. Esta forma urbana es inconexa a la trama urbana existente. De acuerdo a la observación de su evolución física durante el periodo de estudio, el TCU de crecimiento capilar se produce fuera de los límites urbanos, asociados a un trazado informal. Tanto la trama vial como las manzanas son de formas irregulares sin ningún tipo de orden o secuencia entre sí. Los lotes de terrenos se observan también con formas heterogéneas adaptadas a la topografía y de tamaños grandes y medianos. Se combina el

Figura $\mathrm{N}^{\circ} 5$

Crecimiento capilar en Dalcahue, 2005.

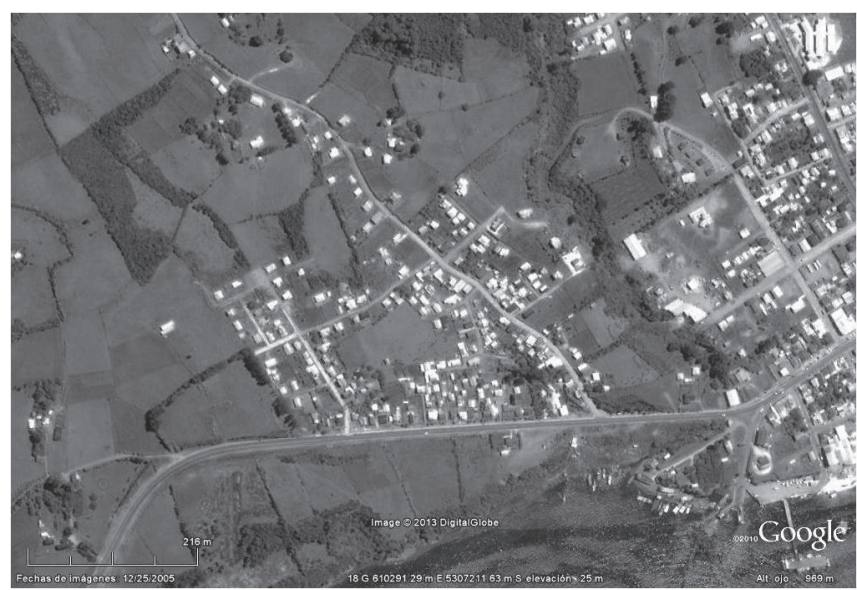

Fuente: Imagen satelital de 2005 (Google Earth). 
uso residencial con actividades agrícolas y ganaderas. Esta forma de crecimiento urbano también significa altos costos de inversión pública en abastecimientos de servicios e infraestructura por lo complejo de las soluciones técnicas necesarias para llegar a todos los domicilios que se encuentran desperdigados por el sinuoso relieve. Sin embargo, al igual que el crecimiento tentacular disperso, este TCU ha sido incorporado a los PRC y LU de manera progresiva. La forma de crecimiento capilar del área urbana es el ejemplo de un tipo de expansión acelerada, informal y desordenada en las ciudades producto de la valorización del suelo anexo y cercano a los centros urbanos mayormente relacionados con la salmonicultura.

\section{Celdas estandarizadas}

Con la valorización de la tierra aneja y cercana a las ciudades, también se activa el mercado de suelo local. Surgen proyectos de vivienda social estatal y privada orientada a diversos sectores sociales. Aunque en Castro y Ancud se concentra la mayoría de la vivienda privada, en el resto de ciudades la vivienda estatal predomina en formas urbanas homogéneas y estandarizadas. Poseen tramas viales lineales o curvas ordenadas de acuerdo a un diseño planificado del emplazamiento. Las manzanas responden a una lógica de máximo aprovechamiento del espacio con di- mensiones factibles de ser divididas en lotes homogéneos (ver Figura $N^{\circ} 6$ ).

Tanto los lotes como las viviendas son de igual forma y tamaño. Es un tipo de urbanización que puede ser reproducido en cualquier lugar y no guarda relación con las tramas urbanas tradicionales. En su interior disponen de los servicios y de la infraestructura básica necesaria para funcionar de manera semiindependiente de los centros urbanos. No se observó la presencia de muros o elementos físicos limitadores del espacio. Pero la misma forma física de este TCU significa la fragmentación espacial de la zona o sector urbano en donde se ubique. Ante la condicionante topográfica siempre presente en las periferias de las ciudades, el TCU de celdas estandarizadas transforma el entorno natural a su favor por medio de la intervención física del relieve realizando grandes movimientos de tierra para crear terrazas semiplanas escalonadas o grandes terrazas planas en las partes altas de las periferias urbanas. A pesar de que estas urbanizaciones estatales o privadas se construyen con la mayoría de la infraestructura y los servicios incorporados, los gastos por concepto de adaptación del entorno al proyecto son cuantiosos. De acuerdo a lo informado por funcionarios municipales de los departamentos de obras públicas y planificación urbana, estos costos incrementan fuertemente los presupuestos de obra. La lógica de

Figura $\mathrm{N}^{\circ} 6$

Proyectos de vivienda estandarizados en Castro, 2008.

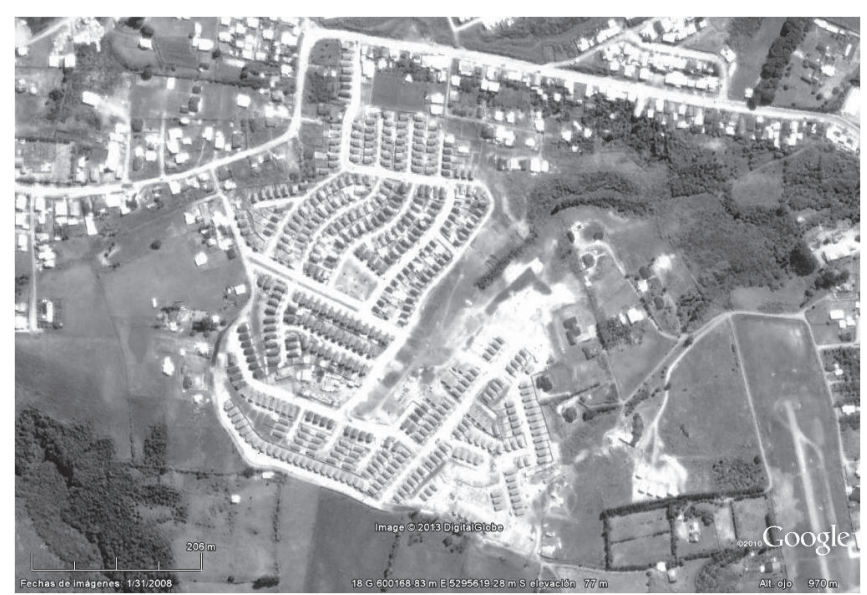

Fuente: Imagen satelital de 2008 (Google Earth). 
construir de esta manera se basa en criterios de rentabilidad. En un terreno más plano se puede construir un mayor número de viviendas al aprovechar al máximo la superficie disponible.

Las aceleradas dinámicas de expansión producto de la presión por suelo urbanizable, gatilladas por el incremento poblacional, demandaron una construcción planificada pero con la mayor cantidad de unidades habitacionales posibles. Se constata una lógica de rápida recuperación del capital invertido superando las barreras espaciales existentes (Harvey, 2004). En este caso es la topografía natural del entorno lo que contiene la expansión de la ciudad. También debe considerarse el impacto de esta forma urbana en el paisaje tradicional chilote. Se destruye un entorno físico natural propio y característico de las periferias rurales de las ciudades de Chiloé y se reemplaza por proyectos de vivienda de baja densidad, de tipología estandarizada y repetible en cualquier otro punto del planeta. Se produce entonces una agresiva suplantación del paisaje tradicional por paisajes artificiales modernos.

\section{Precariedad emergente}

Debido a la agreste topografía de la costa oriental de Chiloé, particularmente en las zonas en que se ubican las ciudades, exis- ten zonas específicas consideradas de riesgo correspondientes a quebradas, laderas con fuertes pendientes o suelo inestable, bordes de río inundables, y borde costero sensible a maremotos o fuertes variaciones de mareas (ver Figura $\mathrm{N}^{\circ} 7$ ).

Las formas tradicionales de ocupación del espacio, planificadas o informales, han evitado por lógica el habitar estas zonas. Sin embargo, la valorización del suelo urbano que surge a partir de las intensas oleadas de inmigración poblacional que arriban a las ciudades, sumado a la ausencia de IPT, o la debilidad de los existentes durante las primeras dos décadas de estudio, convirtieron estos sectores en suelo de bajo costo y accesible para familias de bajos recursos, lo que se puede interpretar como una estrategia de acceso a las oportunidades que ofrecen los centros urbanos. La trama vial es trazada de forma rudimentaria, adaptándose a la topografía y condiciones del entorno. Por lo general, permanecen sin ser asfaltadas indefinidamente, ante la negativa de las administraciones públicas de invertir en zonas de riesgo e informales. Las manzanas son de formas irregulares y sin ninguna lógica de planificación. Los lotes son también de formas irregulares, pero mucho más pequeños que los observados en los TCU anteriores y con una ocupación intensiva del suelo. Son asentamientos humanos altamente densificados $y$, en muchos casos, con graves condiciones de

Ocupación informal de zonas de riesgo en sector Puente Soto, Quellón, 2005.

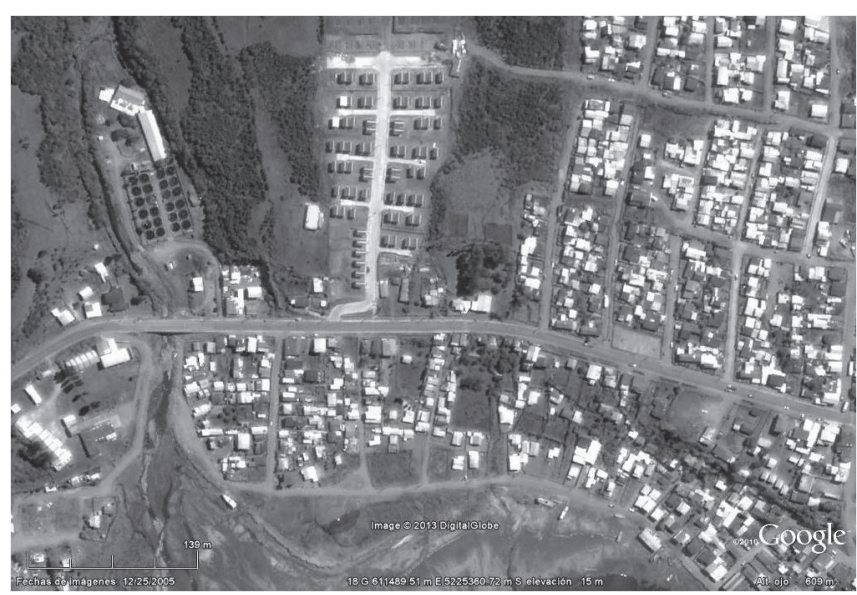

Fuente: Imagen satelital de 2005 (Google Earth). 
hacinamiento e insalubridad. Sin embargo, en la mayoría de las viviendas se observa en sus materiales y estructura la previsión de protegerse del clima invernal con techos de buena calidad y aislamiento térmico básico pero suficiente para el clima local.

\section{Parcelas de agrado}

Las parcelas de agrado son una forma de habitar fuera de la ciudad pero muy relacionada con esta y se distingue dentro de los diferentes procesos de rurbanización dados en las periferias de las ciudades de Chiloé. Son similares al tipo de asentamiento alejado físicamente de las grandes metrópolis pero relacionado a la misma por los continuos flujos de personas, bienes e información. Son habitantes que trabajan y cubren sus necesidades domésticas dentro de la ciudad, pero viven fuera de esta (ver Figura $N^{\circ} 8$ ).

Este TCU está conectado a una vía principal o camino vehicular que conduce hacia la ciudad. Son asentamientos físicamente discontinuos del área urbana pero muy dependientes de esta. En su mayoría son grandes lotes con acceso propio desde las vías y con viviendas de formas heterogéneas y de mayor tamaño que las encontradas dentro de las ciudades. Algunos terrenos mantienen actividades agrícolas y ganaderas para comercialización. Otros realizan actividades como la cría de pequeños animales y agricultura para autoconsumo, a modo de aprovechar los beneficios de contar con un terreno amplio. Las parcelas de agrado se encuentran en ese difuso y amplio borde entre lo rural y lo urbano. Los antiguos atributos tradicionales para definir lo rural como asociado a baja densidad poblacional, viviendas atomizadas, grandes superficies de terrenos y el predominio de actividades económicas primarias, no resultan suficientes para negar a estos espacios la calidad de urbanos. Son áreas ubicadas en las zonas rurales pero estrechamente relacionadas a centros urbanos.

La compra de un vehículo por familia se ha vuelto cada vez más accesible, lo que ha modificado las dinámicas de conectividad. Esto permite una ubicación cercana a las ciudades aprovechando los bajos precios de la tierra rural y la infraestructura vial existente, generando una forma de crecimiento urbano común en las ciudades contemporáneas que vincula las zonas rurales a procesos de ocupación del suelo ligado a grupos sociales con nuevas ambiciones y modos de subsistencia. Así, la presión sobre el suelo urbano se extiende al suelo rural de las periferias en forma de islas entrelazadas por las carreteras. Esta trama vial responde a un trazado sin ninguna planificación adaptándose a la topografía. Sin embargo, no evidencia haber sido hecha con el desorden y la velocidad característicos de la expansión capilar. Es un tipo de consumo

Figura $\mathrm{N}^{\circ} 8$

Parcelas de agrado en vía a sector Lechagua, Ancud, 2006.

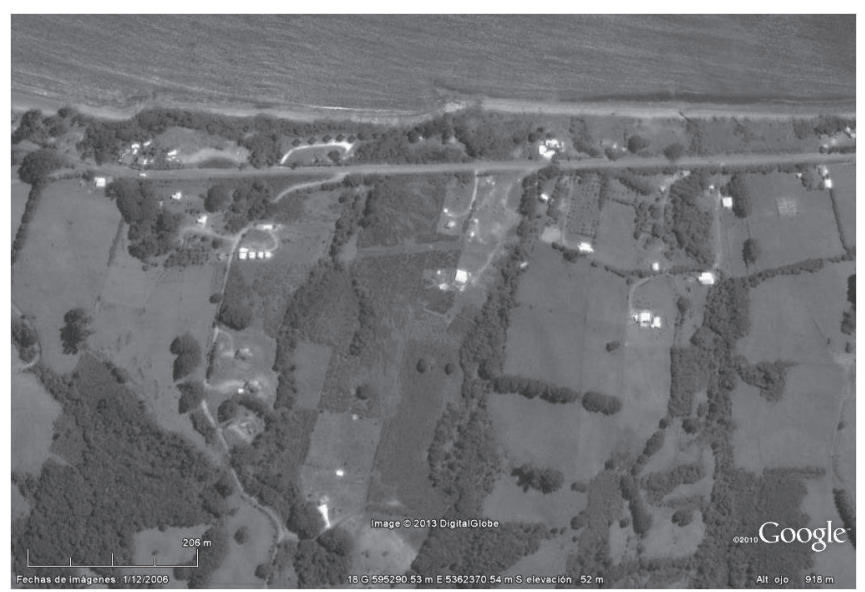

Fuente: Imagen satelital de 2006 (Google Earth). 
de suelo mucho más lento, pero igualmente extenso por las amplias superficies de los loteos. El acceso a servicios e infraestructura sanitaria se resuelve con sistemas de extracción de agua del subsuelo y sistemas de desecho de aguas servidas independientes (letrinas, pozos sépticos). Sin embargo, sí es importante el abastecimiento de energía eléctrica, por lo cual es clave la localización de los terrenos cerca de vías principales.

\section{Emplazamiento industrial}

La industria es también un importante configurador de la forma urbana. En el caso de Chiloé, esta se ubica de preferencia en el borde costero o en el borde de una vía de acceso a la ciudad. Se beneficia de la infraestructura urbana y de los servicios básicos existentes $y$, de cierta forma, actúa como un foco de urbanización atrayendo más vivienda a sus cercanías (ver Figura № 9).

Su localización se inspira en gran medida en factores productivos, pues su criterio también responde al aprovechamiento máximo de los recursos naturales que sirven para dinamizar su producción. Un ejemplo es la ubicación de centros de cultivo de salmones en las orillas de ríos cercanos a su desembocadura al mar y cerca de una vía vehicular principal. Esto les permite acceder a agua dulce para el proceso de cultivo, acceder al borde costero para el embarque y desembarque de biomasa y estar conectados al sistema vial interprovincial para la salida de los productos congelados por camión hacia las ciudades y el continente. En Chiloé predomina la industria salmonera pero también existen emplazamientos industriales para el procesamiento, o acopio y distribución de otros productos acuícolas como los Mytilus chilensis (choritos), Tawera gayi (almejas), Porphyra columbina (luche) y Gracilaria chilensis (peliIlo), entre otros. Estos emplazamientos atraen nuevos habitantes a las periferias de las ciudades. A pesar de esto y del continuo uso de la infraestructura urbana existente, el sector privado no ha desempeñado un rol relevante en los procesos de expansión urbana, de acuerdo a lo informado por representantes de las municipalidades chilotas. Las actividades industriales generan inquietud en torno a los impactos socio-ambientales en las cercanías de la ciudad. La contaminación de los afluentes de agua, del mar y el borde costero con productos derivados de la actividad industrial es ampliamente criticada por la opinión pública local (Fløysand et al., 2010a). La industria integra en su actividad a mano de obra básica que se ubica dentro y en las cercanías de las ciudades. Grandes flujos de personas se trasladan a diario entre distintas comunas para acudir al trabajo. También consume los recursos naturales del entorno como parte de los procesos de transformación del espacio

Figura $\mathrm{N}^{\circ} 9$

Emplazamiento industrial en vía de ingreso a Quemchi, 2005.

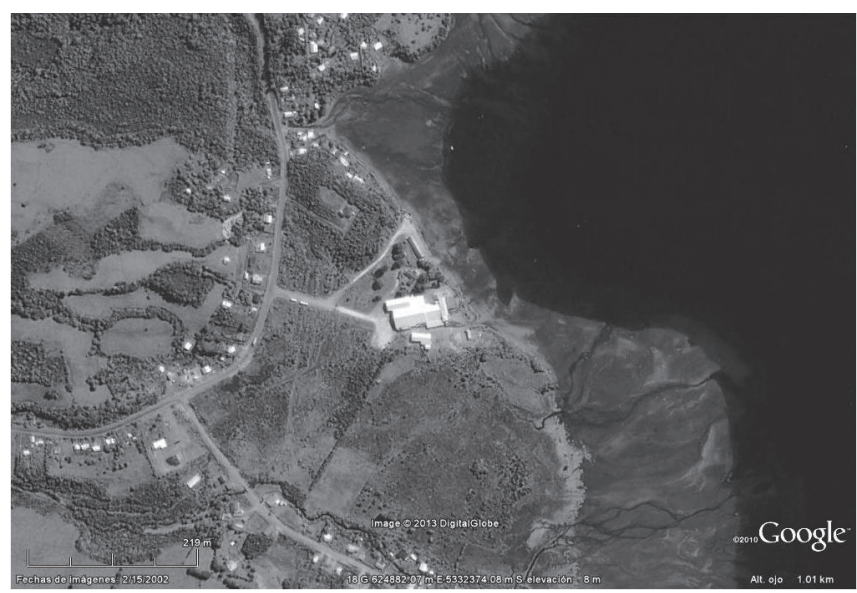

Fuente: Imagen satelital de 2005 (Google Earth). 
en beneficio de la reproducción del capital sobre el territorio.

\section{Densificación de satélites}

Como parte del proceso de rurbanización por efectos del crecimiento acelerado de la ciudad, se densifican los asentamientos humanos ya existentes localizados cerca de los centros urbanos. Villorrios y pequeños poblados rurales próximos a las ciudades reciben nuevos habitantes como consecuencia de la demanda de suelo barato motivado por las oportunidades de trabajo que las pequeñas aglomeraciones urbanas de la costa oriental del archipiélago ofrecen durante el auge del boom salmonero (ver Figura $N^{\circ} 10$ ).

Con el mejoramiento de la infraestructura vial y el desarrollo del sistema de transporte público intercomunal, los flujos se intensificaron. Se fortaleció la relación de conectividad con estas poblaciones tipo satélite, conformándose así una red de poblaciones basada en los tiempos de viaje. Son familias que se relacionan estrechamente con la ciudad, en donde diariamente trabajan, estudian, compran o venden productos. Aunque viven fuera de la urbe, se benefician de sus servicios, equipamientos e infraestructura. La morfología de estos asentamientos no es homogénea. Se produce por la parcelación de terrenos agrícolas y se despliega sobre el suelo rural en base a la creación de nuevas vías o senderos de acceso. Otros poblados mayormente consolidados incrementan su trama urbana con nuevas manzanas. Estos procesos, por estar fuera de los límites urbanos, se escapan del control de la administración pública municipal.

Como señalamos, los TCU no se presentan de manera excluyente en las ciudades analizadas. Las Figuras $\mathrm{N}^{\circ} 11, \mathrm{~N}^{\circ} 12$ y $\mathrm{N}^{\circ}$ 13 representan estos cambios en tres de los casos de estudio, los que se destacan por una transformación especialmente evidente en el período 1979-2008. Las áreas urbanas de Dalcahue, Quemchi y Quellón concentran estos cambios con particular intensidad debido a su dependencia del sector salmonero, aunque se pueden identificar patrones similares en Ancud y Castro, si bien estas ya muestran tendencias a la consolidación de estructuras urbanas existentes al inicio del auge salmonero y su base económica está fuertemente apoyada en el sector terciario.

\section{Morfología orgánica de una expansión acelerada}

Los enfoques historicistas y de tipologías que se encuentran en los estudios de morfología urbana internacional ofrecen guías para entender las especificidades de los contextos locales (Ehlers, 2011; Kropf,

Figura $N^{0} 10$

Densificación de satélites en Dalcahue, 2005.

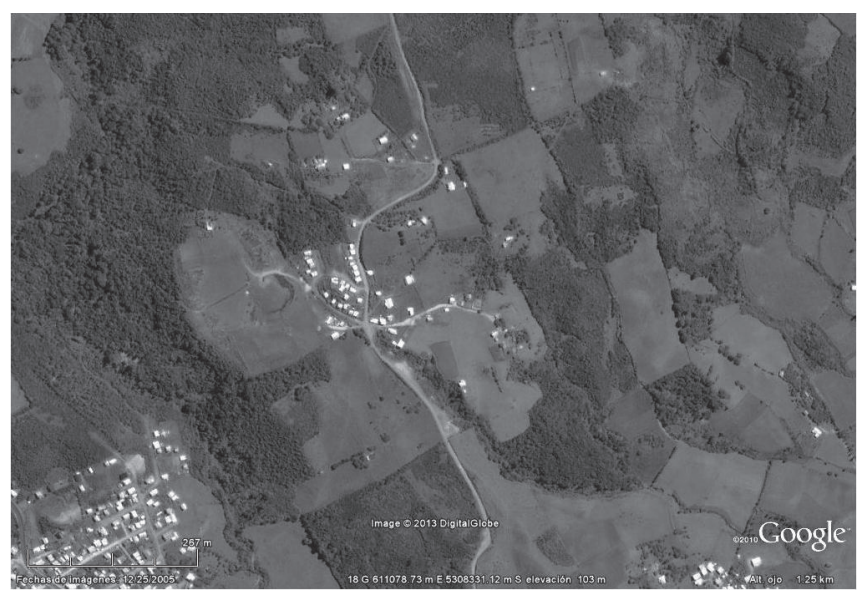

Fuente: Imagen satelital de 2005 (Google Earth). 
Figura $N^{0} 11$

Crecimiento urbano de Dalcahue, 1979-2008.

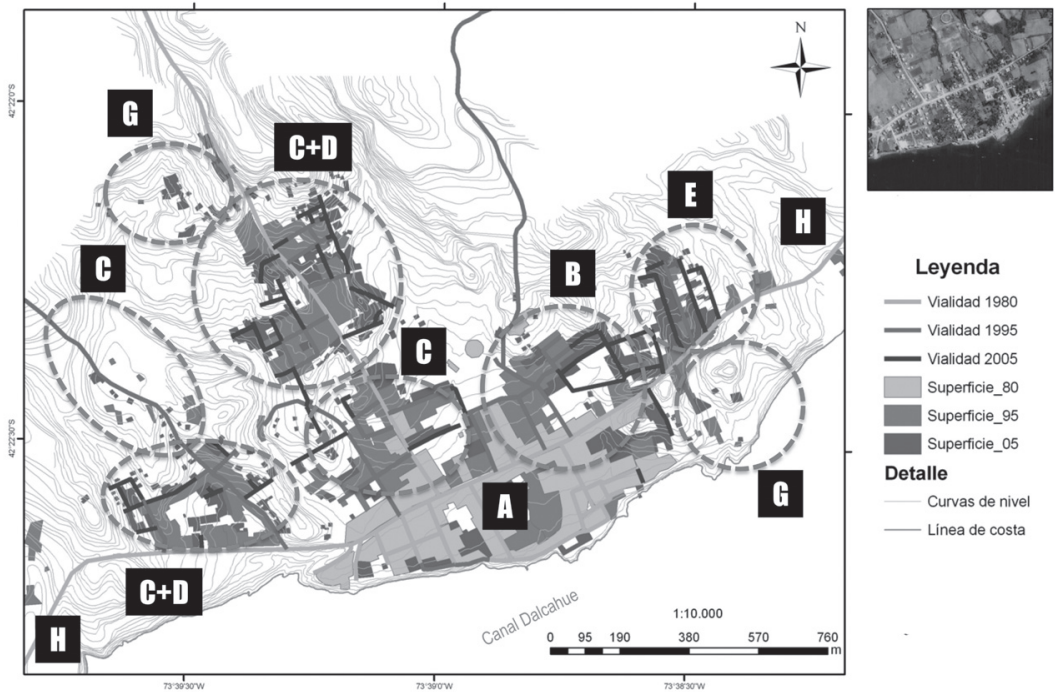

Fuente: Autores, con base en fotografías aéreas (SAF, 1980, 1995), imagen satelital (Google Earth 2005) y límite urbano (I. Municipalidad de Dalcahue, 2003).

Figura $\mathrm{N}^{\circ} 12$

Crecimiento urbano de Quemchi, 1979-2008.

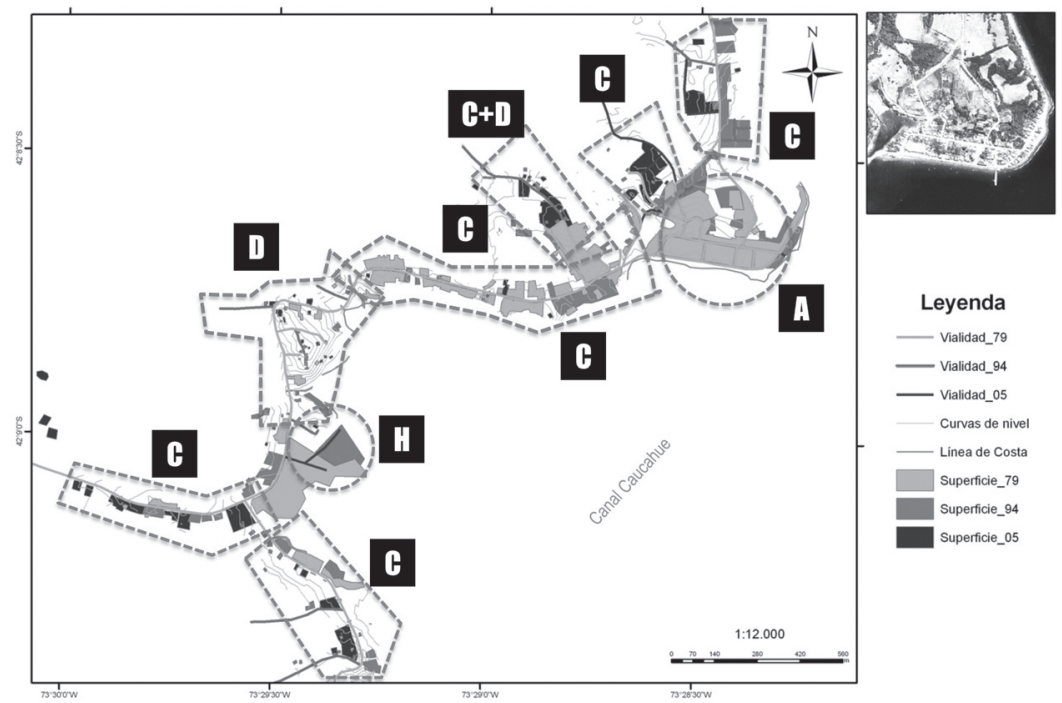

Fuente: Autores, con base en fotografías aéreas (SAF, 1979, 1995), imagen satelital (Google Earth, 2005) y límite urbano (I. Municipalidad de Quemchi, 2001). 


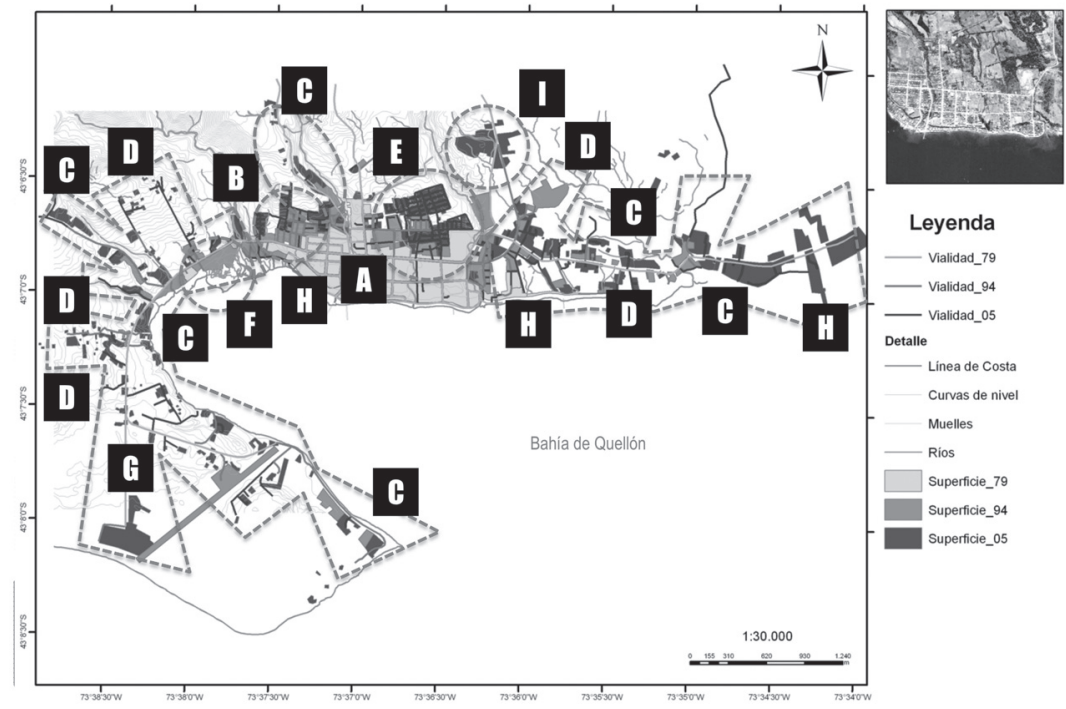

Fuente: Autores, con base en fotografías aéreas (SAF, 1979, 1994), imagen satelital (Google Earth, 2005) y plan regulador comunal (I. Municipalidad de Quellón, 2005).

2009). Sin embargo, estudios nacionales de patrones dominantes, fijados particularmente en las ciudades más grandes (Gauthier \& Gilliland, 2006; Oliveira, 2013), a menudo representan una simplificación de la diversidad y heterogeneidad de formas urbanas subnacionales. A pesar del hecho que muchas ciudades son de mediana y pequeña escala y concentran poblaciones de menor número, estos centros son claves como nodos de dinámicas urbanas, especialmente en términos de inserción en la economía global. Es por eso que es valioso estudiar su evolución, especialmente en Chile, debido a la orientación de tantas regiones hacia los mercados de exportación.

Diversas condicionantes locales modifican en diferentes grados las mutaciones socio-espaciales en cada ciudad de Chiloé. La complejidad de la topografía del emplazamiento y la relativa debilidad de los IPT son dos de las principales. Entre estos dos factores se encuentran una explicación de la forma orgánica de la expansión y su velocidad. La reconfiguración geográfica que impulsan los procesos de acumulación de capital desplegados en la provincia de Chiloé impactan con diferente intensidad a cada poblado pero en un contexto común de transformación socioespacial. La conformación acelerada de una clase asalariada, la urbanización y los flujos de personas se expresan en los acelerados procesos urbanos que experimentan las pequeñas ciudades de Chiloé como consecuencia de oleadas migratorias provinciales, regionales y nacionales conformadas mayoritariamente por familias en búsqueda de oportunidades de trabajo en labores no especializadas. A pesar de que las cinco ciudades se ubican sobre el borde costero oriental y norte del archipiélago, los emplazamientos comparten una geomorfología natural relativamente común en términos generales. Cada sector en donde se ubican los centros urbanos de principios de la década de 1980 tuvo un relieve particular que, de cierta forma, orientó la expansión urbana durante las tres décadas siguientes. Por ende, las formas urbanas de las cinco ciudades resultaron distintas y adaptadas al espacio natural. Aunque esta afirmación a primera vista resulta evidente, esta condicionante es un factor muy importante a valorar cuando se reflexiona sobre la morfología de ciudad que el capital construye o altera. Se puede afirmar que la velocidad del crecimiento orgánico implica un aprovechamiento de la topografía, 
también una vulnerabilidad asociada con localización en partes de esta topografía donde las condiciones por suelo, pendiente y acceso complican las vidas diarias de sus habitantes; este es especialmente el caso del TCU de precariedad emergente, donde hay evidencia del aprovechamiento de suelos poco aptos para vivienda pero rápidamente consolidados por migrantes de bajos ingresos.

Durante el período 1979-2008, independiente de que aparezcan paulatinamente instrumentos de planificación para cada una de las ciudades estudiadas, la tendencia general es que el proceso de urbanización represente formas no planificadas de ocupar el espacio, donde las escalas de redes globalizadas definen el territorio, y no la escala de regulación local o regional (Swyngedouw, 2004). La parcelación de tierra agrícola e improductiva en lotes de forma irregular lo evidencia. Asimismo, el trazado desordenado de los senderos que posteriormente se transforman en calles da la forma a las nuevas manzanas. La mancha urbana sube por las laderas del relieve y se adapta a este. El alto contenido residencial de esta expansión alberga la mano de obra asalariada asociada a la industria y a las actividades económicas complementarias a esta. Esta desregulación desde el sector público deja espacio a una ocupación espacial impulsada mayoritariamente por individuos en la forma de loteos y decisiones de localización familiar, lo que refiere a un contexto glocal en el sentido que dichos individuos establecen relaciones directamente con los procesos de acumulación de capital (Swyngedouw, 2004). Por otro lado, se observa también una morfología urbana más técnicamente planificada en determinadas zonas. La urbanización en viviendas y lotes estandarizados se integra al proceso urbano de las ciudades antes y durante el período de estudio, pero es principalmente una forma de regular un proceso ya en movimiento, con resultados limitados debido a la lentitud de la respuesta frente a los cambios producidos. La mayor cantidad de consumo de suelo para la implementación de estos proyectos se produce durante el período de industrialización de la provincia de Chiloé. Este tipo de morfología urbana también presenta una faceta agresiva respecto al entorno topográfico natural en la medida que lo adapta a sus necesidades por medio de grandes movimientos de tierra para lograr terrazas o pequeñas mesetas que se adicionan a la ciudad existente. Esta práctica de urbanización resulta cuestionable por la fuerte alteración al paisaje tradicional chilote y los altos costos por la adaptación del terreno al proyecto, aunque puede argumentarse que la inversión se justifica en términos de que facilita las labores constructivas, se genera ahorro económico en dichas labores, así como también se facilita la instalación y distribución de servicios básicos. Futuros procesos de urbanización replicando esta morfología darán cuenta de un paisaje compuesto por múltiples terrazas de viviendas repetidas en serie y perfectamente ordenadas, característico de ciudades integradas a flujos económicos globales como sucede en las periferias urbanas de Santiago y en otras ciudades globalizadas de América Latina y el mundo, producto a la 'destrucción creativa' del capital global (Harvey, 2007).

Carlos de Mattos (2010) plantea que las metamorfosis urbanas atribuibles a la globalización no implican necesariamente una pérdida de la identidad local en cada asentamiento. Sin embargo, como se puede observar en el proceso urbano de Chiloé, el paisaje urbano de sus periferias está mutando en su dinámica de crecimiento, morfología urbana y tipología de las viviendas, debido a las velocidades contrapuestas entre lo público y lo privado. Aunque este último tema -la vivienda- escapa a los alcances del presente artículo, es también un importante efecto de la transformación del espacio por el capital. Las nuevas viviendas de zinc predominantes en las nuevas superficies de expansión evidencian una contraposición con la tradicional vivienda chilota y se vinculan a un cambio en la relación con los recursos naturales, pero también al acceso a ellos en el mercado. Estos son los palimpsestos que se acumulan y traslapan en las ciudades, en especial en sus periferias (Harvey, 2004).

En el caso de las ciudades de Chiloé sí existiría una importante afectación a sus improntas geográficas tradicionales evidenciada en la lectura de las huellas físicas que deja la ola transformadora de la glocalización en el territorio (Capel, 2002). La ausencia o debilidad de los IPT existentes en las ciudades de Chiloé durante el periodo 1979-2008 es la segunda condicionante a considerar en este 
acelerado y desordenado crecimiento orgánico. En las cinco ciudades el boom salmonero provoca un acelerado proceso de cambio para el cual no existió una planificación urbana debidamente preparada, en términos de velocidad y capacidad de anticipación. Las actualizaciones de Ios PRC de Ancud y Castro se hacen a partir de la segunda década de este auge industrial; Quemchi actualiza su LU, que data de 1941, recién a inicios de la década de 2000. Los casos de Dalcahue, Quellón y Quemchi presentan un atraso aun mayor pues solo a partir de esa década tuvieron sus primeros IPT. Es decir, la mayor parte del tiempo en que experimentaron las más importantes y aceleradas mutaciones socioespaciales estuvieron sin herramienta de planificación (Román, 2009).

El análisis de los TCU permite exponer la existencia de una importante paradoja: durante la ausencia o debilidad de los IPT en las ciudades, estas crecieron aceleradamente en superficie consumiendo gran cantidad de suelo nuevo en sus periferias, pero sorprende que posterior a la actualización de IPT vigentes o a su implementación por primera vez el consumo de suelo aumenta en lugar de disminuir. Si se examina detenidamente el contenido de los PRC y LU, estos tienen en común la incorporación masiva de suelo urbanizable o la ampliación de los límites del área urbana. Así, la respuesta de la planificación urbana en Chiloé ante las transformaciones impulsadas por la nueva geografía económica ha sido la de fomentar la creación de nuevo espacio físico urbano extendiendo constantemente los bordes de la ciudad, promoviendo una economía asociada a la provisión de infraestructura y servicios urbanos (Harvey, 2004), no obstante ha abierto también una oportunidad a nuevos residentes a acceder a zonas residenciales equipadas con servicios básicos a diferencia de barrios completos creados durante el período de desregulación, que aun no logran adecuados estándares de agua potable, alcantarillado o accesos (Fløysand \& Román, 2008).

Esta observación abre un nuevo sendero en la apreciación del proceso urbano en Chiloé pues estos nuevos esfuerzos por regular son concurrentes con procesos análogos dirigidos a la industria salmonera, especialmente tras la crisis sanitaria que llevó a redefinir los estándares en dicho sector y, en consecuencia, requirió el establecimiento de parámetros definidos de localización a través de los IPT; efectivamente una 're-regulación' del territorio (Fløysand, 2010a; Van Apeldoorn et al., 2012). A la luz de estos antecedentes, los TCU definidos en este artículo ofrecen una síntesis gráfica de la relación entre regulación desde el Estado y el rol del capital en la transformación del territorio, y sugieren una persistencia de un modelo de desarrollo que toma como punto de partida el crecimiento económico.

La experiencia de las ciudades chilotas no es única. Muchas ciudades de mediana y pequeña escala que han sido insertas en la economía global a través de los circuitos de capital desde 1950 (el 'global shift' de la internacionalización de la producción), han sufrido de similares experiencias de crecimiento veloz y orgánico, con poca regulación, organización y planificación (ver Sabatini y Arenas, 2000). Frente a este escenario, las posibilidades de asegurar un desarrollo urbano más sustentable han sido superados por las presiones de capital y migración. En definir las formas urbanas que surgen de procesos orgánicos de crecimiento, hay lecciones que sirven para tomadores de decisión para 'reregular' el territorio, también para prevenir cambios futuros. También hay evidencia de experiencias de morfología urbana que alimentan los debates internacionales, para superar su 'miopía euro-(norte)americana' y 'glocalizar' los debates en este campo de investigación.

\section{Referencias bibliográficas}

AMTMANN, C. \& BLANCO, G. Efectos de la salmonicultura en las economías campesinas de la Región de Los Lagos, Chile. Revista Austral de Ciencias Sociales, 2001, No 5, P. 93-106.

ARENAS, F.; ANDRADE, B.; QÜENSE, J. \& LE BAIL, J. Las mutaciones socio-espaciales de la costa oriental de la Isla Grande de Chiloé. Revista Geográfica de Chile Terra Australis, 2001a, Vol. 46, p. 201-217.

ARENAS, F.; ANDRADE, B. \& QÜENSE, J. La valorización de un espacio periférico: el 
caso de la costa oriental de la Isla Grande de Chiloé. Revista de Geografía Norte Grande, 2001b, Vol.28, p. 79-90.

BAILLY, A. Pour un développement rurbain durable. Revue d'Economie Régionale et Urbaine, 2009, Vol. 2, p. 231-238.

BAILLY, A. \& BOURDEAU-LEPAGE, L. Concilier désir de nature et préservation de I'environnement: vers une urbanisation durable en France. Géographie, économie, société, 2011, Vol.13, p. 27-43.

BARRETT, G. ; CANIGGIA, M., \& READ, L. There are More Vets than Doctors in Chiloé: Social and Community Impact of the Globalization of Aquaculture in Chile. World Development, 2002, Vol. 30, № 11, p. 1951-1965.

BARTON, J.R. ¿Revolución azul? El impacto de la acuicultura del salmón en Chile. EURE, 1997, Vol. 22., № 68, p. 57-76.

BARTON, J.R. Salmon aquaculture and Chile's "export-led" economy. Norwegian Journal of Geography, 1998, Vol. 52, № 1, p. 37-47.

BARTON, J.R. \& FLØYSAND, A. The political ecology of Chilean salmon aquaculture, 1982-2010: a trajectory from economic development to global sustainability. Global Environmental Change, 2010, Vol. 20, No 4, p. $739-752$.

BARTON, J.R.; GWYNNE, R. \& MURRAY, W. Competition and cooperation in the semiperiphery: closer economic partnership and sectoral transformations in Chile and New Zealand. The Geographical Journal, 2007, Vol. 173, Nº 4, p. 224-241.

BARTON, J.R., GWYNNE, R. \& MURRAY, $W$. Transformations in resource peripheries: an analysis of the Chilean experience. Area, 2008, Vol. 40, № 1, p. 24-33.

CAPEL, H. La morfología de las ciudades. Vol. I. Sociedad, cultura y paisaje urbano. Barcelona: Ediciones del Serbal, 2002.

DE MATTOS, C. Globalización y metamorfosis urbana en América Latina. Quito: OLACCHI- MDMQ, 2010.
DE MATTOS, C. Globalización y metamorfosis urbana en América Latina. Quito: Organización Latinoamericana y del Caribe de Centros Históricos OLACCHI y Municipio del Distrito Metropolitano de Quito (MDMQ), 2010.

DE SOLÁ-MORALES, M. Las formas de crecimiento urbano. Barcelona: Ediciones UPC, 1997.

DICKEN, P. Global Shift: Mapping the changing contours of the world economy. New York: The Guildford Press, 2011.

EHLERS, E. City models in theory and practice: a cross- cultural perspective. Urban Morphology, 2011, Vol. 15, № 2, p. 97-119.

ENGELS, F. The condition of the working class in England. Oxford: Oxford University Press, 2009.

FLØYSAND, A. y ROMÁN, Á. Industria salmonera, sistemas de innovación y desarrollo local: el punto de vista de las municipalidades de Chiloé. Bergen: Universidad de Bergen, 2008.

FLØYSAND, A.; BARTON, J.R. y ROMÁN, Á. La doble jerarquía del desarrollo económico y gobierno local en Chile: el caso de la salmonicultura y los municipios chilotes. EURE, 2010a, Vol. 36, No 108, p. 123-148.

FLØYSAND, A.; HAARSTAD, H. \& BARTON, J.R. Global-economic imperatives, crisis generation and spaces of engagement in the Chilean aquaculture industry. Norwegian Journal of Geography, 2010b, Vol. 64, p. 199210.

GAUTHIER, P. \& GILLILAND, J. Mapping urban morphology: a classification scheme for interpreting contributions to the study of urban form. Urban Morphology, 2006, Vol. $10, N^{\circ} 1$, p. 41-50.

GAUTHIEZ, B. The history of urban morphology. Urban Morphology, 2004, Vol. 8, No 2, p. 71-89.

GEREFFI, G. \& KORZENIEWICZ, M. (editors). Commodity Chains and Global Capitalism. Westport, CT: Praeger. 1994. 
GIL, J.; BEIRÃO, J.N.; MONTENEGRO, N. \& DUARTE, J.P. On the discovery of urban typologies: data mining the many dimensions of urban form. Urban Morphology, 2012, Vol. $16, \mathrm{~N}^{\circ} 1$, p. 27-40.

GOBANTES, C. Migraciones laborales en un archipiélago en transformación: Chiloé ante al desarrollo de la salmonicultura. Santiago de Chile: Memoria para optar al título de Antropólogo Social, Universidad de Chile, 2011.

GRENIER, P. Chiloé et les chilotes: Marginalité et dépendance en Patagonie Chilienne. Aix-en-Provence: Édisud, 1984.

HAGGETT, P. Análisis locacional en la geografía humana. Barcelona: Editorial Gustavo Gili, 1975.

HALL, P. Ciudades del mañana: historia del urbanismo en el siglo XX. Barcelona: Ediciones del Serbal, 1996.

HARVEY, D. Social Justice and the City. Baltimore: Johns Hopkins University Press, 1973.

HARVEY, D. Mundos urbanos posibles. En: RAMOS, M. (editor). Lo urbano en 20 autores contemporáneos. Barcelona: Ediciones UPC, 2004, p.177-199.

HARVEY, D. Breve historia del neoliberalismo. Madrid: Akal, 2007.

IIZUKA, M. Organizational capability and export performance: the salmon industry in Chile. In: Druid Winter Conference, 22-24 January of 2004, Aalborg.

INSTITUTO NACIONAL DE ESTADÍSTICAS (INE). Chile: XV censo nacional de población y IV de vivienda: Recuento preliminar. Santiago de Chile: Instituto Nacional de Estadísticas, 1982.

INSTITUTO NACIONAL DE ESTADÍSTICAS (INE). Censo de población y vivienda, Chile 1992: Resultados generales. Santiago de Chile: Instituto Nacional de Estadísticas, 1993.
INSTITUTO NACIONAL DE ESTADÍSTICAS (INE). Censo 2002: resultados. Santiago de Chile: Instituto Nacional de Estadísticas, 2003.

INSTITUTO NACIONAL DE ESTADÍSTICAS (INE). Resultados preliminares censo de población y vivienda 2012. Santiago de Chile: Instituto Nacional de Estadísticas, 2012.

KATZ, J. Salmon Farming in Chile. In: CHANDRA, V. (editor) Technology, Adaptation and Exports. How some developing countries got it right. Washington, DC: World Bank, 2006, p.193-224.

KAY, C. Reflections on Latin American rural studies in the neoliberal globalization period: a new rurality? Development and Change, 2008, Vol. 39, Nº 6, p. 915-943.

KROPF, K.S. Conceptions of change in the built environment. Urban Morphology, 2001, Vol. 5, $\mathrm{N}^{\circ} 1$, p. 29-42.

KROPF, K.S. Aspects of urban form. Urban Morphology, 2009, Vol. 13, №2, p. 105-120.

LEVY, A. Urban morphology and the problem of a modern urban fabric: some questions for research. Urban Morphology, 1999, Vol. 3, No 2, p. 79-85.

MATURANA MIRANDA, F. y ARENAS, F. El policentrismo en Chile: medición exploratoria para el sistema de ciudades de las regiones de La Araucanía, de Los Ríos y de Los Lagos. Revista de Geografía Norte Grande, 2012, No 52, p. 37-56.

MONTIEL, F. Chiloé: historias de viajeros. Castro: Ilustre Municipalidad de Castro, 2010.

MUNIZAGA, G. Tipos y elementos de la forma urbana. Aplicación de Estrategias. Santiago de Chile: Ediciones Pontificia Universidad Católica de Chile, 1993.

MURRAY, W.E. Geographies of Globalization. Abingdon: Routledge, 2006.

OECD. National Urban Policy Reviews. The case of Chile 2013. Paris: OCDE, 2013. 
OLIVEIRA, V. The study of urban form: reflections on national reviews. Urban Morphology, 2013, Vol. 17, № 2, p. 85-92.

OSMOND, P. The urban structural unit: towards a descriptive framework to support urban analysis and planning. Urban Morphology, 2010, Vol. 14, № 1, p. 5-20.

RAMÍREZ, E.; MODREGO, F.; MACÉ, J.C. y YÁÑEZ, R. Dinámicas Territoriales en Chiloé Central: La Fuerza de las Coaliciones Extra Territoriales. Santiago de Chile: PDTR-RIMISP, 2009.

ROMÁN, Á. Gobernabilidad para el desarrollo local en Chiloé: nuevos desafíos generados por la salmonicultura en un contexto de cambio global. Santiago de Chile: Tesis de Magíster, Pontificia Universidad Católica de Chile, 2009.

SABATINI, F. y ARENAS, F. Entre el Estado y el mercado: resonancias geográficas y sustentabilidad social en Santiago de Chile. EURE, 2000, Vol. 26, № 79, p. 95-113.

SWYNGEDOUW, E. Globalisation or 'Glocalisation'? Networks, territories and rescaling. Cambridge Review of International Affairs, 2004, Vol. 17, № 1, p. 25-48.

VAN APELDOORN, B., DE GRAAFF, N. \& OVERBEEK, $\mathrm{H}$. The reconfiguration of the global State-capital nexus. Globalizations, 2012, Vol. 9, № 4, 471-486.

VERNEZ MOUDON, A. Urban morphology as an emerging interdisciplinary field. Urban Morphology, 1997, Vol. 1, p. 3-10.

WHEELER, S. The evolution of built landscapes in metropolitan regions. Journal of Planning Education and Research, 2008, Vol. 27, p. 400-416.

WHITEHAND, J.W.R. The structure of urban landscapes: strengthening research and practice. Urban Morphology, 2009, Vol. 13, $N^{\circ} 1$, p. 5-27.

WHITEHAND, J.W.R. Issues in urban morphology. Urban Morphology, 2012, Vol. 16, $\mathrm{N}^{\circ} 1$, p.55-65.

WORLD BANK. World Development Report 2009: Reshaping economic geography. New York: World Bank Group, 2009. 